\title{
A family with massive acute vitamin $D$ intoxication
}

\author{
P. F. Down \\ M.B. B.S., M.R.C.P. \\ A. POLAK
M.D., F.R.C.P. \\ R. J. REGAN \\ M.B. B.S., M.R.C.P. \\ Department of Renal Medicine, University of Southampton, and Wessex Regional Renal \\ Unit, St Mary's Hospital, Portsmouth
}

\begin{abstract}
Summary
Acute massive vitamin D overdosage occurred in a family after eating food cooked in a nut oil containing 5 million units of vitamin $D_{3} / \mathrm{ml}$. The plasma vitamin $D$ was 55 and 60 i.u. $/ \mathrm{ml}$ in the father and mother respectively, and $9.6 \mathrm{i} . \mathrm{u} . / \mathrm{ml}$ in their 11-month-old infant (normal range, 0-1.6 i.u./ml). All the family presented with symptoms of hypercalcaemia and the infant responded quickly to prednisone. After steroids had failed to control the hypercalcaemia in the parents, neutral phosphate was successful, although necessary for 9 months. Before phosphate therapy it was shown that both parents were in strongly negative calcium balance, indicating that the vitamin $D$ was mobilizing calcium from bone. Eleven years later all 3 patients are well but a renal biopsy in one of them shows persistent nephrocalcinosis.
\end{abstract}

\section{Introduction}

Most reported cases of vitamin $\mathrm{D}$ poisoning have resulted from therapeutic use of the vitamin and intoxication has generally developed after prolonged treatment. The present report concerns accidental overdosage of vitamin $\mathrm{D}$, and is also unusual in that the overdose was massive and acute and affected 3 members of the same family. Because of the exceptionally high dose, the toxicity persisted and required treatment for an unusually long time.

\section{Analytical Methods}

Calcium and creatinine in serum were measured using a Technicon Autoanalyser. Faecal and urinary calcium were measured by atomic absorption spectrophotometry.

\section{Case Histories}

Mr B, aged 24, presented after vomiting for 4 days. On admission there were no abnormal signs, but the vomiting continued, and his conjunctivae became suffused. His serum calcium was found to be $4 \mathrm{mmol} / \mathrm{l}$.

Mrs B, a 24-year-old Indian, was admitted 12 days after her husband with a history of nausea, vomiting and colicky abdominal pain for one week.

She had marked weakness and sensory loss in all her limbs with absent tendon reflexes indicating an acute polyneuropathy. Her serum calcium was 4 $\mathrm{mmol} / \mathrm{l}$.

The 11-month-old infant was admitted the day after his mother, having had mild vomiting for $24 \mathrm{hr}$. He had no abnormal physical signs, but his serum calcium was 4.3 . $\mathrm{mmol} / 1$.

Hypercalcaemia in all 3 members of a family suggested an exogenous cause. Subsequently an oil intended as a concentrate for animal feeds but used by the family for cooking was found to contain 5 million units of vitamin $\mathrm{D}_{3} / \mathrm{ml}$. Plasma samples taken from father, mother and infant 5 weeks after the ingestion of the vitamin $\mathrm{D}$ were later bio-assayed and found to contain 55 i.u. $/ \mathrm{ml}, 60$ i.u. $/ \mathrm{ml}$ and 9.6 i.u./ml respectively (normal range, 1.6 i.u./ml) (Fig. 1).

\section{Progress}

The infant was treated with prednisone, $15 \mathrm{mg} /$ day, and his serum calcium fell to $3 \mathrm{mmol} / \mathrm{l}$ within 3 days. The prednisone was tailed off during the next 3 weeks, by which time his serum calcium was $2.63 \mathrm{mmol} / \mathrm{l}$. His subsequent growth and development have been normal.

The parents were fed with a diet of $<7.5 \mathrm{mmol}$ calcium/day which was also low in vitamin $D$. They received large doses of prednisone, and later hydrocortisone, but the serum calcium showed no consistent fall (Fig. 2). Mrs B had anorexia and although she was fed via a nasogastric tube for 2 months she lost about $25 \%$ of her body weight. Her neuropathy 


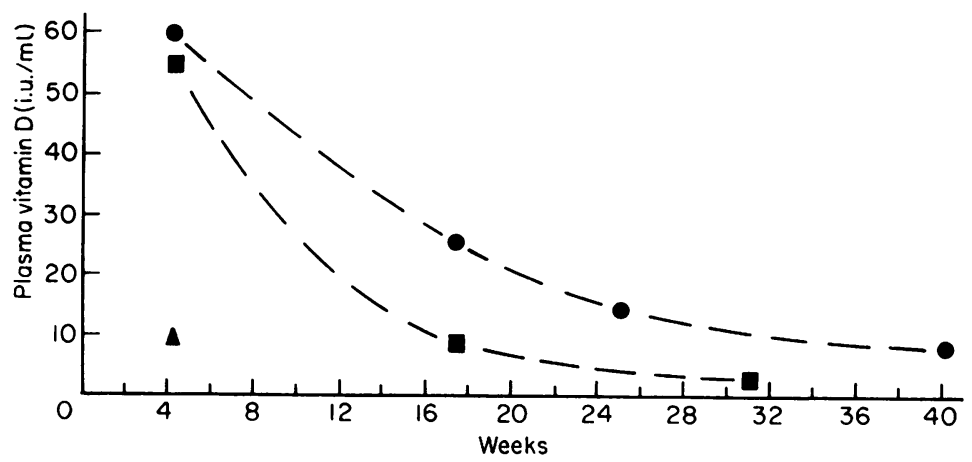

FIG. 1. Plasma vitamin D (i.u./ml) in the $\mathrm{B}-$ family (normal range: 0-1.6 i.u./ml). Mother; $\mathbf{a}$ father; $\Delta$ infant.

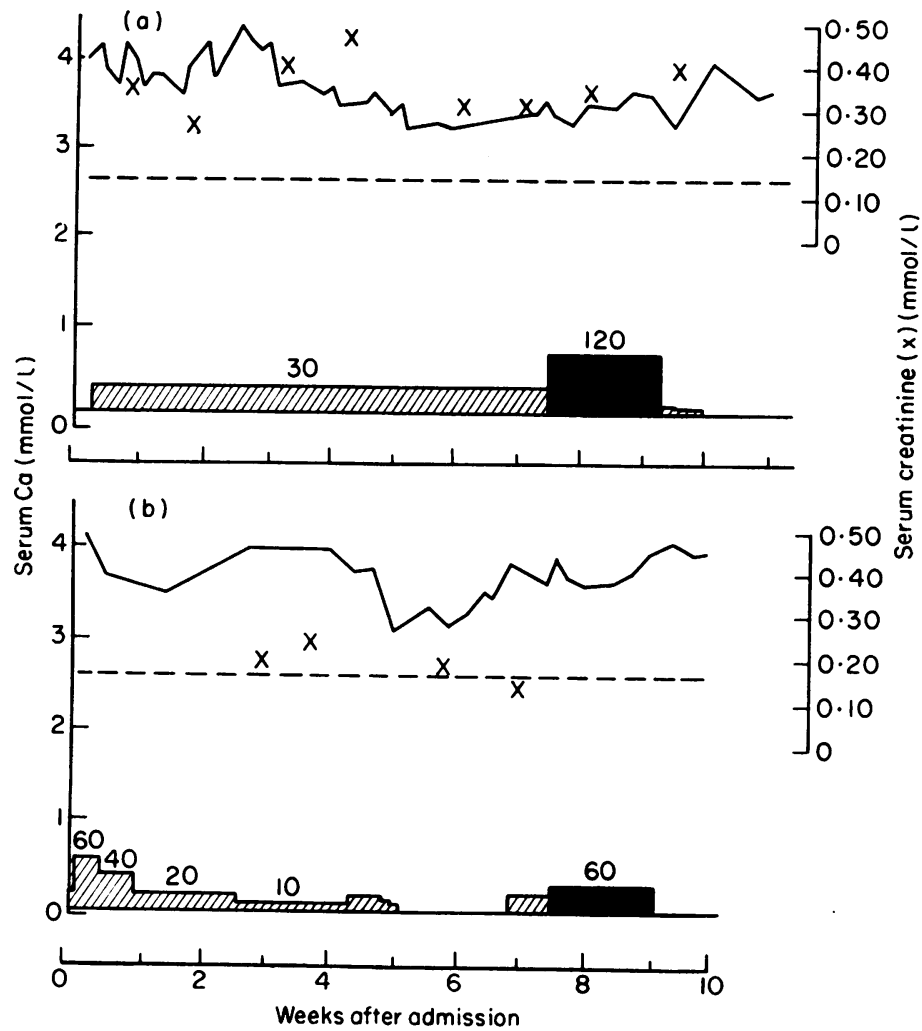

FIG. 2. Serum calcium in Mr B (a) and Mrs B (b) during steroid treatment (calcium intake $<7.5 \mathrm{mmol} /$ day). - - Upper limit of normal. W Prednisone (mg/day); $\square$ hydrocortisone (mg/day).

improved rapidly. Three weeks after admission she spontaneously aborted a 10-week fetus. Both she and her husband developed renal failure (Table 1). Three months after admission they remained hypercalcaemic. He had developed band keratopathy and she was emaciated. Frequent comparisons of their estimated calcium intake with their urinary calcium

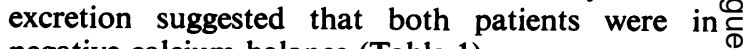
negative calcium balance (Table 1).

After 9 weeks, steroid therapy was abandoned, 
TABLE 1. Mean serum calcium (MSC), mean serum creatinine (MSCr) and mean urinary calcium (MUC) in $\mathrm{Mr} \mathrm{B*}$ (body weight $61 \mathrm{~kg}$ ) and Mrs $\mathrm{B} \dagger$ (body weight $33.2 \mathrm{~kg}$ ), diet containing $<7.5 \mathrm{mmol} \mathrm{Ca} /$ day

\begin{tabular}{|c|c|c|c|c|c|c|}
\hline \multirow{2}{*}{$\begin{array}{l}\text { Week after } \\
\text { admission }\end{array}$} & \multicolumn{2}{|c|}{$\begin{array}{c}\mathrm{MSC} \\
\mathrm{mmol} / 1\end{array}$} & \multicolumn{2}{|c|}{$\begin{array}{c}\mathrm{MSCr} \\
\mathrm{mmol} / 1\end{array}$} & \multicolumn{2}{|c|}{$\underset{\mathrm{mmol} / 24 \mathrm{hr}}{\text { MUC }}$} \\
\hline & $*$ & + & $*$ & $\dagger$ & & $t$ \\
\hline 1 & 3.95 & - & 0.35 & - & 12.9 & - \\
\hline 2 & $4 \cdot 10$ & - & 0.25 & - & $8 \cdot 7$ & - \\
\hline 3 & $4 \cdot 15$ & 4.0 & 0.42 & $0 \cdot 16$ & 5.0 & $17 \cdot 1$ \\
\hline 4 & 3.65 & 3.85 & 0.50 & 0.22 & $5 \cdot 5$ & $11 \cdot 5$ \\
\hline 5 & 3.45 & $* * 3.4$ & - & - & $7 \cdot 5$ & $10 \cdot 5$ \\
\hline 6 & $3 \cdot 25$ & $* * 3.7$ & 0.32 & $0 \cdot 15$ & $12 \cdot 4$ & $12 \cdot 2$ \\
\hline 7 & - & 3.8 & 0.30 & $0 \cdot 11$ & $10 \cdot 4$ & $14 \cdot 7$ \\
\hline 8 & $3 \cdot 3$ & $3 \cdot 5$ & 0.34 & - & $8 \cdot 5$ & 15.0 \\
\hline 9 & $3 \cdot 7$ & - & 0.40 & - & $10 \cdot 9$ & - \\
\hline
\end{tabular}

** During weeks 5 and 6 Mrs B was not on steroids.

All other data in the table were obtained during steroid therapy.

but despite further reduction of the calcium intake to $2.5 \mathrm{mmol} /$ day the hypercalcaemia persisted. Two weeks after stopping steroids a formal balance study using chromium sesquioxide marking of faeces confirmed that $<2 \mathrm{mmol} /$ day of calcium was being passed in the stools, while the urinary loss was greater than the dietary intake (Fig. 3).

Neutral phosphate* was now given orally. In Mr B it induced a dramatic fall in the serum and urinary calcium (Figure 3), and he immediately felt better and lost his nausea. Mrs B developed painful, red conjunctivae within $6 \mathrm{hr}$ of her first dose containing one $\mathrm{g}$ of phosphorus. After a further dose, her serum calcium fell from $3.3 \mathrm{mmol} / 1$ to $1.95 \mathrm{mmol} / 1$ (Fig. 3) and she developed tetany which was relieved by intravenous calcium gluconate $(2 \cdot 3 \mathrm{mmol}$ calcium). The serum phosphate in this episode rose to 3.5 $\mathrm{mmol} / \mathrm{l}$ and the conjunctival infection, which improved as soon as this fell, was probably caused by calcium phosphate deposition. Phosphate therapy was withheld for 5 days, during which time she became hypercalcaemic again, and calcium reappeared in her urine (Fig. 3).

Subsequently both husband and wife required treatment with moderate calcium restriction and oral neutral phosphate for 9 months (Fig. 4). The phosphate dose required to maintain the serum calcium at about $2.75 \mathrm{mmol} / 1$ ranged from $1.5-6 \mathrm{~g} /$ day. Since completing phosphate treatment, the serum calcium has remained normal, the serum creatinine

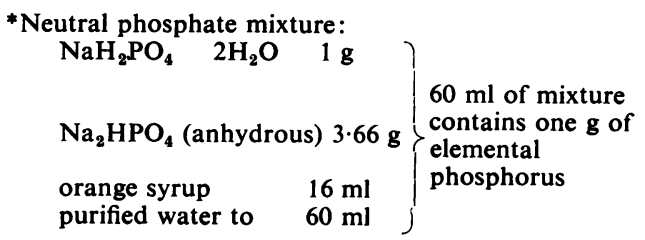

concentrations have fallen to $0.13 \mathrm{mmol} / 1$ and 0.08 $\mathrm{mmol} / \mathrm{l}$ in husband and wife respectively and their maximum urine osmolality readings on $16 \mathrm{hrs}$ ' water deprivation were $920 \mathrm{mosmol} / \mathrm{kg}$ and 855 mosmol $/ \mathrm{kg}$. Seven months after the overdose, $\mathrm{Mr}$ B had a renal biopsy which showed nephrocalcinosis. Nine years later, they are both well, with no apparent renal impairment, and she has had a second normal pregnancy. A second renal biopsy in $\mathrm{Mr} \mathrm{B}$ shows that the nephrocalcinosis is still present.

\section{Discussion}

This family consumed a nut oil which contained 5 million units of vitamin $D_{3} / \mathrm{ml}$, a concentration far greater than can be found in any preparation for human consumption. The plasma levels at 5 weeks were more than 30 times the upper limit of the normal range in man for this assay. Moreover, they were still markedly elevated after 6 months (Fig. 1).

These cases illustrate 2 known actions of vitamin $D$ which in excess can lead to hypercalcaemia. The first is the promotion of calcium absorption by the gut. The second is the mobilization of calcium from bone (Hess, Benjamin and Gross, 1931), which presumably accounts for the great excess of the urinary calcium over the intake. The authors can find no previous report of a persistently negative calcium balance in humans poisoned by vitamin $D$ although it has been shown in rats (Clark, 1961). There is, however, radiographic evidence of bone dissolution in man (Christensen, Liebman and Sosman, 1951) a feature which, although evident in the present patients was not sufficiently marked to reproduce in photographs.

Steroid therapy is often successful in correcting vitamin D-induced hypercalcaemia (Dent, 1956), but when first prednisone and then hydrocortisone failed, 

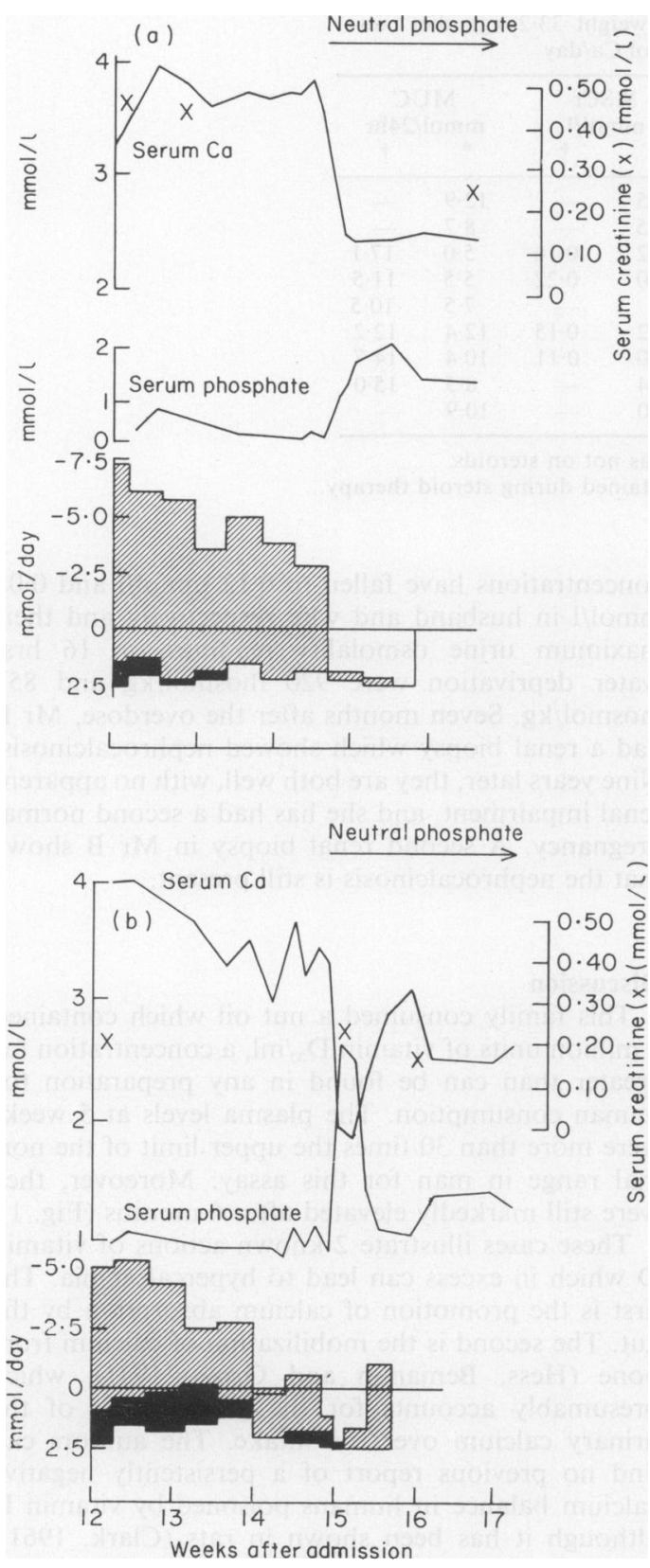

Fig. 3. Calcium balance in Mr B (a) and Mrs B (b) while off treatment showing hypercalcaemia in the presence of a marked negative calcium balance. Steroids had been stopped 2 and 3 weeks previously respectively. Neutral phosphate lowered the serum calcium and produced a profound fall in urine calcium. Urine calcium; $\mathbf{d a e c a l} \mathrm{Ca}$. presumably because of the severity of the underlying vitamin $\mathrm{D}$ poisoning, the use of neutral phosphat was felt to be justified.

It is known to be highly effective in controlling hypercalcaemia (Goldsmith and Ingbar, 1966) and? to do so by depositing calcium phosphate in the bodye Some of this deposition may occur in bone by stimu을. lation of new bone formation and bone mineral $\frac{\bar{s}}{\frac{}{4}}$

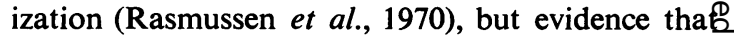
some deposition may be ectopic (Herbert et al.œ 1966; Breuer and Le Bauer, 1967) led the present authors to hold neutral phosphate in reserve in treating $\mathrm{Mr}$ and Mrs B. In the event it proved ex $\overrightarrow{\vec{\omega}}$ tremely effective in lowering their serum calcium although the acute development of conjunctivab injection in Mrs B confirmed that not all the removed. calcium was deposited in bone. The maintenancer dose in both patients was adjusted to prevents symptoms rather than to keep the serum calcium in the normal range. It was gradually reduced as the serum calcium fell, presumably owing to diminishing vitamin D intoxication. Even so, both patients required phosphorus $6 \mathrm{~g}$ /day for several months, and it was 9 months before therapy could be stopped.

Besides his band keratopathy, Mr B had nephro calcinosis in a renal biopsy taken 4 months after the start of phosphate treatment, and this was stiln present in a second biopsy taken 9 years later $\overrightarrow{0}$ Nephrotomograms at the time of each biopsy faited to show calcium; which accords with the findingsof Iverson and Brun (1951).

The improvement in serum creatinine as the serums calcium fell was to be expected, as it is known thato hypercalcaemia depresses the glomerular filtration rate (Epstein, 1960). However, it seemed probable that some permanenet renal damage would remain $\overrightarrow{\vec{b}}$ after severe hypercalcaemia of 3 months' duration, 3 and the renal biopsies in $\mathrm{Mr} \mathrm{B}$ confirmed this. It is therefore encouraging that the serum creatinine values had fallen to normal after 9 months and haves not risen 9 years later. This, together with the en 3 . couraging results of the urine concentrating tes suggest that the residual damage is unlikely to give rise to ill health.

Mrs B's initial acute polyneuropathy did nok resemble the cases published by Henson (1966) in whom muscle weakness was accompanied by in- $\rightarrow$ creased tendon reflexes, and it subsided before there was any fall in serum calcium.

Spontaneous abortion has not previously been described in vitamin $\mathbf{D}$ poisoning but is not sur prising in view of Mrs B's severe metabolic dis- $-\widetilde{w}$ turbance. There is an increased incidence of fetalo complications and stillbirths in patients with hypere parathyroidism (Ludwig, 1962).

Despite the risk of ectopic calcification,? phosphate treatment appears preferable to steroids? 


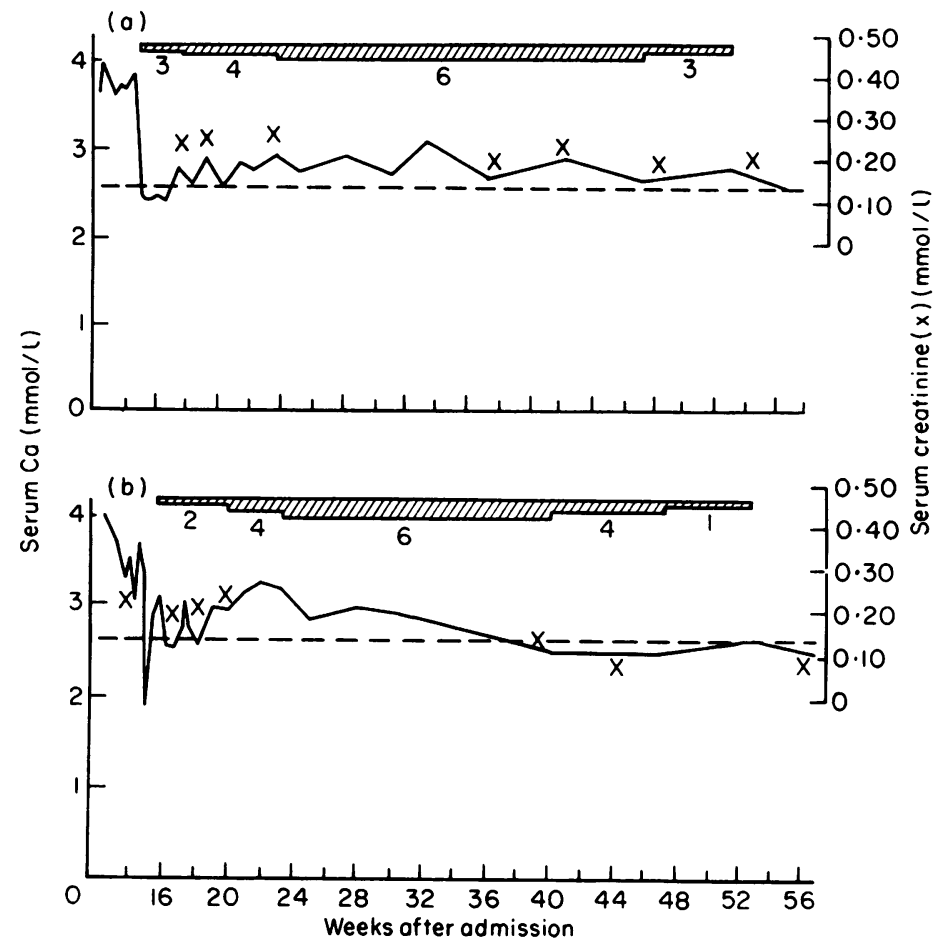

FIG. 4. Long-term response to neutral phosphate therapy in $\mathrm{Mr} \mathrm{B}$ (a) and Mrs B (b). Dotted line shows upper limit of normal. For details of treatment in weeks 12 to 17 , see Fig. 3. $\mathscr{W}$ Neutral phosphate (g/day).

especially when it is likely that high dose or longterm steroids (Shetty, 1975) might otherwise be necessary. Cellulose phosphate has been recommended where long-term therapy is contemplated (Pak et al., 1968) and its successful use in one patient has been reported (Qureshi, Moore and Goldsmith, 1974). Intravenous sodium sulphate results in a marked increase in urinary calcium excretion, and a fall in serum calcium levels in a variety of hypercalcaemic states (Charmajian and Bethune, 1966) but there are no reports of its use in hypervitaminosis $D$, although one patient was treated successfully with sodium sulphate given by mouth (Kowarski et al., 1961). Porcine calcitonin, which was not available for Mr and Mrs B in 1968, has been successful in the treatment of hypercalcaemia due to vitamin D intoxication (Buckle, Gamlen \& Pullen, 1972) which is of interest because its main action is to inhibit bone resorption (Raisz et al., 1968; Reynolds et al., 1968). Further experience may show whether neutral phosphate is to be preferred, at least when prolonged therapy is required.

\section{Acknowledgments}

We are greatly indebted to Professor S.W. Stanbury for the plasma vitamin D bio-assays and to Dr W.F.J. Cuthbertson for measuring the vitamin D content of the ingested oil. Dr R.I. Gleadle first suggested the possibility of hypercalcaemia in this family.

\section{References}

Breuer, R.I. \& Le Bauer, J. (1967) Caution in the use of phosphate in the treatment of severe hypercalcemia. Journal of Clinical Endocrinology and Metabolism, 27, 695.

Buckle, R.M., Gamlen, T.R. \& Pullen, I.M. (1972) Vitamin $\mathbf{D}$ intoxication treated with porcine calcitonin. British Medical Journal, 3, 205.

Chakmajian, Z.H. \& Bethune, J.E. (1966) Sodium sulfate treatment of hypercalcemia. New England Journal of Medicine, 275, 862.

Christensen, W.R., Liebman, C. \& Sosman, M.C. (1951) Skeletal and periarticular manifestations of hypervitaminosis D. American Journal of Roentgenology, 65, 27.

Clark, I. (1961) Agents affecting the removal of skeletal radiocalcium and radiophosphorus from intact and parathyroidectomized rats. In: The Parathyroids, Ed. by Greep, R. and Talmage, R.N. p. 183. Charles C. Thomas, Springfield, Illinois.

DENT, C.E. (1956) Cortisone test for hyperparathyroidism. British Medical Journal, 1, 230. 
Epstein, F.H. (1960) Calcium and the kidney. Journal of Chronic Diseases, 11, 255.

GolDSMITH, R.S. \& INGBAR, S.H. (1966) Inorganic phosphate treatment of hypercalcemia of diverse etiologies. New England Journal of Medicine, 271, 1.

Henson, R.A. (1966) The neurological effects of hypercalcaemia with special reference to primary hyperparathyroidism. Journal of the Royal College of Physicians of London, 1 (1), 41.

Herbert, L.E., Lemann, J., Petersen, J.R. \& Lennon, E.J. (1966) Studies of the mechanism by which phosphate infusion lowers serum calcium concentration. Journal of Clinical Investigation, 45, 1886.

Hess, A.F., Benjamin, H.R. \& Gross, J. (1931) Source of excess calcium in hypercalcemia induced by irradiated ergosterol. Journal of Biological Chemistry, 94, 1.

IVERSON, P. \& BRUN, C. (1951) Aspiration biopsy of the kidney. American Journal of Medicine, 11, 324.

Kowarski, A., Shapiro, T.R., Biezunski, N. \& Nowarski, C. (1961) Hypervitaminosis D. Effect of treatment with sodium sulfate. Pediatrics, 22, 1004.

LuDWIG, G.D. (1962) Spontaneous abortion, still birth, neonatal death and tetany. New England Journal of Medicine, 267, 637.

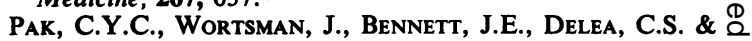
BARTTER, F.C. (1968) Control of hypercalcemia, with $\subset$ cellulose phosphate. Journal of Clinical Endocrinology and Metabolism, 28, 1829.

QURESH, M.S.A., MOORE, R. \& GoldSMith, H.J. (1974) Sodium cellulose phosphate in vitamin $\mathrm{D}$ intoxication. British Journal of Urology, 46, 489.

Raisz, L.G., Au, W.Y.W., Friedman, J. \& NiemanN, I. $\frac{\overline{\bar{c}}}{\bar{T}}$ (1968) In: Calcitonin: Proceedings of the Symposium on $\overparen{D}$ Thyrocalcitonin and the C Cells. (Ed. by Taylor, S.) p. 215. Heinemann, London.

Rasmussen, H., Feinblatt, J., Nagata, N. \& Pechet, M. (1970) Effect of ions upon bone cell function. Federation Proceedings, 29, 1190.

Reynolds, J.J., Dingle, J.T., Gudmundsson, T.V. \& $\vec{\omega}$ MacIntyre, I. (1968) In: Calcitonin: Proceedings of the Symposium on Thyrocalcitonin and the C Cells. (Ed. by Taylor, S.), p. 223. Heinemann, London.

ShetTy, K.R. (1975) Protracted vitamin D intoxication. if Archives of Internal Medicine, 135, 986. 